\title{
HuGE systematic review and meta-analysis demonstrate association of CASP-3 and CASP-7 genetic polymorphisms with cancer risk
}

\author{
S. Yan, Y.Z. Li, X.W. Zhu, C.L. Liu, P. Wang and Y.L. Liu \\ Department of Urological Surgery, \\ The Fourth Affiliated Hospital of China Medical University, \\ Shenyang, Liaoning, China \\ Corresponding author: Y.L. Liu \\ E-mail: cmu4h_lyl@126.com \\ Genet. Mol. Res. 12 (2): 1561-1573 (2013) \\ Received June 6, 2012 \\ Accepted November 31, 2012 \\ Published May 13, 2013 \\ DOI http://dx.doi.org/10.4238/2013.May.13.10
}

\begin{abstract}
Genetic variations in the caspase genes CASP-3 and CASP-7 are known to be involved in apoptosis, cytokine maturation, cell growth and differentiation. Polymorphisms of CASP-3 and CASP7 genes have been increasingly recognized as important regulators in the development of cancer. However, whether there is a specific association is still controversial. Therefore, we made a Human Genome Epidemiology review and meta-analysis to explore the association between polymorphisms of CASP-3 and CASP-7 genes and cancer risk. Based on the inclusion criteria, we examined 9 case-control studies, with a total of 3142 cancer cases and 3670 healthy controls. Meta-analysis results showed that the homozygote (CC) of rs2705897 in the CASP-3 gene is positively associated with cancer susceptibility [odds ratio (OR) $=4.36,95 \%$ confidence interval $(\mathrm{CI})=1.26-15.11, \mathrm{P}=0.02]$, while the $\mathrm{C}$ allele and $\mathrm{C}$ carrier $(\mathrm{TC}+\mathrm{CC})$ of rs1049216 are negatively associated with cancer risk $(\mathrm{OR}=0.81,95 \% \mathrm{CI}=0.69-0.95, \mathrm{P}=0.01 ; \mathrm{OR}=0.78$,
\end{abstract}


$95 \% \mathrm{CI}=0.63-0.97, \mathrm{P}=0.02$, respectively). The $\mathrm{G}$ allele and $\mathrm{G}$ carrier of rs4647603 (A/G) in CASP-3 had positive associations with cancer susceptibility $(\mathrm{OR}=1.69,95 \% \mathrm{CI}=1.37-2.09, \mathrm{P}<0.001 ; \mathrm{OR}=1.93$, $95 \% \mathrm{CI}=1.26-2.93, \mathrm{P}=0.002$, respectively). The $\mathrm{T}$ allele of $\mathrm{rs} 12415607$, the $\mathrm{G}$ allele and homozygote (GG) of rs2227310, and homozygote (CC) of rs3124740 also had positive associations with cancer risk $(\mathrm{OR}=1.18$, $95 \% \mathrm{CI}=1.02-1.37, \mathrm{P}=0.03 ; \mathrm{OR}=1.17,95 \% \mathrm{CI}=1.01-1.34, \mathrm{P}=0.03$; $\mathrm{OR}=1.34,95 \% \mathrm{CI}=1.04-1.74, \mathrm{P}=0.03 ; \mathrm{OR}=1.30,95 \% \mathrm{CI}=1.04-1.63$, $\mathrm{P}=0.02$, respectively). In addition, homozygote (AA) of rs 11196418 showed a significant negative association with cancer risk $(\mathrm{OR}=0.36$, $95 \% \mathrm{CI}=0.14-0.93, \mathrm{P}=0.03$ ). These meta-analysis results demonstrated that CASP-3 and CASP-7 genetic polymorphisms are involved in the pathogenesis of cancer.

Key words: Caspase 3; Genetic polymorphism; Susceptibility; Cancer; Meta-analysis

\section{INTRODUCTION}

Cancers occur in numerous tissues with multiple etiologies and varying tumor progression (Evan and Vousden, 2001) and is one of the greatest threats to human health (He et al., 2008). The number of people who die from cancer increases annually. Cell apoptosis (programmed cell death) is a rather significant biological process that maintains the integrity and homeostasis of multicellular organisms (Thompson, 1995). During the process of cell apoptosis, abnormal cell death or maturation might cause cancer. Previous studies have suggested that caspases (cysteinyl aspartate-specific proteinases) may be responsible for some of the cellular changes associated with apoptosis (Cohen, 1997; Budihardjo et al., 1999).

Caspases are important mediators of apoptosis. Caspase-3 (also known as CPP32, SCA-1, and CPP32B) is a cysteine protease encoded by the CASP-3 gene located at chromosome 4q34 (Lakhani et al., 2006). Caspase-7, an apoptosis-related cysteine peptidase, is encoded by the CASP-7 gene located at chromosome 10q25.1-10q25.2 (Teixeira et al., 2008). Caspase-3 and caspase-7 are executioner caspases (Yu et al., 2009). Caspase-3 plays a central role in the execution phase of cell apoptosis, cleaving and activating caspases 6,7 , and 9 (Lakhani et al., 2006).

Single nucleotide polymorphisms (SNPs) are the most common form of human genetic variation and may contribute to individual susceptibility to cancer (Son et al., 2006). In recent years, many studies have been conducted to investigate the associations between CASP-3 and CASP-7 genes and cancer susceptibility. Several reports have shown that CASP-3 is mutated in various types of cancers, such as pediatric neuroblastoma (Wang and Zheng, 2004), breast cancer (Devarajan et al., 2002), and gastric carcinoma (Isobe et al., 2004). However, these studies have not determined the exact role of CASP-3 and CASP-7 genetic polymorphisms in cancer risk, and conclusions about this link remain controversial. Therefore, we performed a Human Genome Epidemiology (HuGE) review and meta-analysis by including the most recent and relevant publications to gather statistical evidence of the associations that have been investigated. 


\section{MATERIAL AND METHODS}

\section{Identification of eligible studies}

PubMed, Cochrane Library, Embase, Web of Science, Springerlink, China National Knowledge Infrastructure, and the Chinese Biomedical Database were extensively searched to identify relevant studies published by May 10, 2012. The search terms included ("caspase-3" or "CASP 3" or "Caspase 3" [Mesh] or "caspase-7" or "CASP 7" or "Caspase 7" [Mesh]), ("SNPs" or "SNP" or "polymorphism, genetic" [Mesh]), and ("cancer" or "tumor" or "Neoplasms" [Mesh]). The references in eligible studies and textbooks were also manually reviewed to find potentially eligible studies. The included studies had to meet the following criteria: 1) studies used a case-control design to examine associations between CASP-3 or CASP-7 genetic polymorphisms and cancer risk; 2) all patients had a diagnosis of a malignant tumor confirmed by pathological examination of a surgical specimen; 3) the frequencies of alleles or genotypes in case and control groups could be extracted; and 4) the language of publication was English or Chinese. Studies were excluded when they were 1) not case-control studies about CASP-3 or CASP-7 genetic polymorphisms and cancer risk; 2) based on incomplete data; 3) reporting irrelevant or overlapping data; and 4) meta-analyses, letters, reviews, or editorials.

\section{Data extraction}

Using a standardized form, 2 reviewers (S. Yan and Y.Z. Li) extracted data from published studies independently to obtain the necessary information. The following information was extracted from each of the articles included: first author, year of publication, country, language, ethnicity, study design, diagnostic criteria, source of cases and controls, number of cases and controls, mean age, sample, cancer types, genotype methods, polymorphism genotype frequency, and evidence of Hardy-Weinberg equilibrium (HWE) in controls. In cases of conflicting evaluations, an agreement was reached after a discussion with a third reviewer (Y.L. Liu).

\section{Quality assessment of included studies}

Two reviewers (J.W. Zhu and C.L. Liu) independently assessed the quality of selected papers according to a modified Strengthening the Reporting of Observational Studies in Epidemiology quality score system (von Elm et al., 2007; Zhang et al., 2011). Forty assessment items related to the quality appraisal were rated in this meta-analysis with a scale ranging from 0 to 40 . Scores of $0-20,20-30$, and 30-40 were defined as low, moderate, and high quality, respectively. Disagreement was resolved through discussion with a third reviewer (Y.L. Liu).

\section{Statistical analysis}

The odds ratio (OR) and $95 \%$ confidence interval $(95 \% \mathrm{CI})$ were calculated using Review Manager Version 5.1.6 [provided by Cochrane Collaboration; http://ims.cochrane.org/ revman/download (accessed August 9, 2012)] and STATA Version 12.0 (Stata Corp., College Station, TX, USA). Between-study variations and heterogeneities were estimated using the Cochran Q statistic (Higgins and Thompson, 2002; Zintzaras and Ionnidis, 2005). A P value of $\leq 0.05$ was considered a manifestation of statistically significant heterogeneity. 
We also quantified the effect of heterogeneity using the $\mathrm{I}^{2}$ test. $\mathrm{I}^{2}$ represents the proportion of inter-study variability that can be attributed to heterogeneity rather than to chance with a range of 0 and $100 \% . I^{2}$ values of 25,50 , and $75 \%$ were defined as low, moderate, and high estimates, respectively. When a significant $\mathrm{Q}$-test $(\mathrm{P}<0.10)$ or an $\mathrm{I}^{2}$ of $>50 \%$ indicated heterogeneity across studies, the random-effect model was used for meta-analysis or the fixed-effect model was used. We tested whether genotype frequencies of controls were in HWE using the chi-square test. Sensitivity analysis was mainly performed through sequential omission of individual studies.

Publication bias was investigated using the Begger funnel plot, and the funnel plot asymmetry was assessed with the Egger linear regression test (Peters et al., 2006). Statistical significance was reached when the $\mathrm{P}$ value of the Egger test was $<0.05$. All $\mathrm{P}$ values were twosided. To ensure the reliability and accuracy of the results, 2 reviewers (S. Yan and Y.Z. Li) populated the data in the statistical software programs independently and obtained the same results.

\section{RESULTS}

\section{Characteristics of the studies included}

The search strategy retrieved 105 potentially relevant studies. According to the inclusion criteria, 9 studies (Xie, 2004; Lan et al., 2007; Hosgood et al., 2008; Lee et al., 2009; Ulybina et al., 2009; Xu et al., 2009; Lei, 2010; Ni et al., 2011; Mittal et al., 2012) were included in the meta-analysis and 96 were excluded. The flow chart of study selection is shown in Figure 1. The 9 case-control studies selected included 3142 cases and 3670 healthy controls, which evaluated the relationship between CASP-3 or CASP-7 genetic polymorphisms and cancer risk. The publication year of the studies involved ranged from 2004 to 2012. All patients fulfilled the diagnostic criteria of malignant neoplasm confirmed by pathological examination of a surgical specimen. The source of controls was a healthy population. Five SNPs in the CASP-3 gene and 6 SNPs in the CASP-7 gene were addressed. The HWE test was performed on the genotype distribution of the controls in all the studies included and all were in $\operatorname{HWE}(\mathrm{P}>0.05)$. All quality scores of the studies included were $>20$ (moderate-high quality). The characteristics and methodological quality of the studies included are summarized in Table 1. The genotype distributions of CASP-3 and CASP-7 genetic polymorphisms in case and control groups are shown in Table 2.

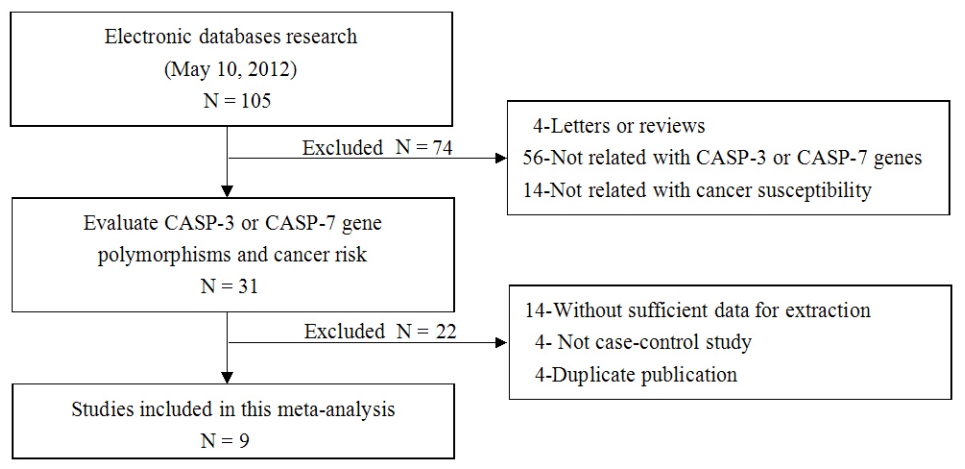

Figure 1. Flow chart shows the study selection procedure. 
CASP-3 and CASP-7 genes and cancer risk

1565

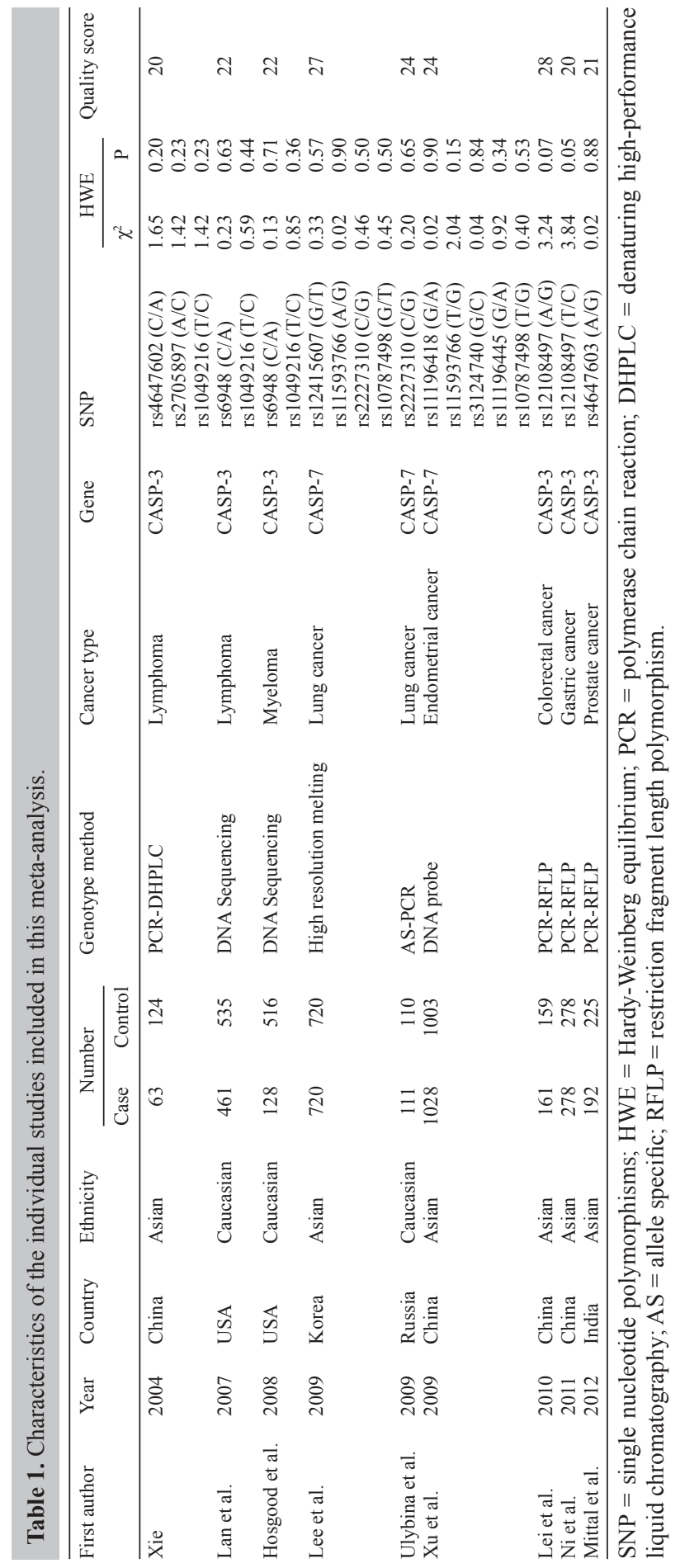




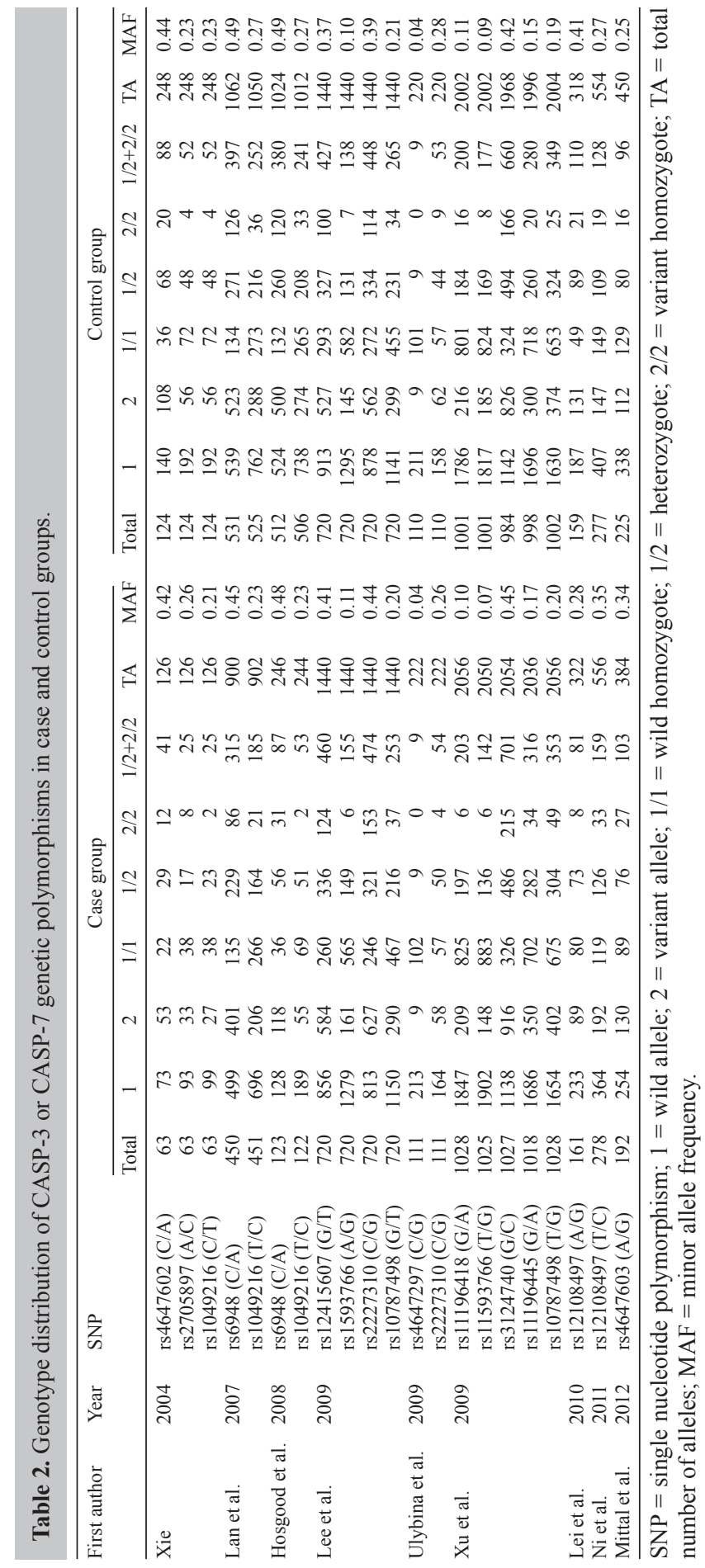




\section{Association between CASP-3 gene polymorphisms and cancer risk}

A summary of the meta-analysis findings of the association between CASP-3 gene polymorphisms and cancer risk is provided in Table 3. The meta-analysis result showed that the homozygote (CC) of rs 2705897 in the CASP-3 gene had a positive association with cancer susceptibility $(\mathrm{OR}=4.36,95 \% \mathrm{CI}=1.26-15.11, \mathrm{P}=0.02)$, whereas the $\mathrm{C}$ allele and $\mathrm{C}$ carrier $(\mathrm{TC}+\mathrm{CC})$ of $\mathrm{rs} 1049216$ showed negative associations with cancer risk $(\mathrm{OR}=0.81,95 \% \mathrm{CI}=$ $0.69-0.95, \mathrm{P}=0.01$, and $\mathrm{OR}=0.78,95 \% \mathrm{CI}=0.63-0.97, \mathrm{P}=0.02$, respectively), suggesting that the $\mathrm{C}$ allele and $\mathrm{C}$ carrier $(\mathrm{TC}+\mathrm{CC}$ ) of rs1049216 might decrease the risk of cancer (see Figure 2). However, no significant connection was found in rs4647602, rs6948, or rs 12108497 (all $\mathrm{P}>0.05$ ). The significance of the pooled OR in all individual analyses was not influenced excessively by omitting any single study.

\begin{tabular}{|c|c|c|c|c|c|c|c|c|}
\hline \multirow[t]{2}{*}{ Polymorphisms } & & \multirow[t]{2}{*}{ Cancer } & \multirow[t]{2}{*}{ Control } & \multirow[t]{2}{*}{ OR $(95 \% \mathrm{CI})$} & \multirow[t]{2}{*}{$P$ value } & \multicolumn{2}{|c|}{ Heterogeneity } & \multirow[t]{2}{*}{ Effect model } \\
\hline & & & & & & $\mathrm{P}$ & $\mathrm{I}^{2}$ & \\
\hline \multirow[t]{4}{*}{ rs4647602 (C/A) } & A allele & $53 / 126$ & $108 / 248$ & $0.94(0.61-1.45)$ & 0.78 & - & - & \multirow[t]{4}{*}{ Fixed } \\
\hline & $\mathrm{CA}+\mathrm{AA}$ & $41 / 63$ & $88 / 124$ & $0.76(0.40-1.46)$ & 0.41 & - & - & \\
\hline & AA & $12 / 63$ & $20 / 124$ & $1.22(0.56-2.70)$ & 0.62 & - & - & \\
\hline & $\mathrm{CA}$ & $29 / 63$ & $68 / 124$ & $0.70(0.38-1.29)$ & 0.26 & - & - & \\
\hline \multirow[t]{4}{*}{ rs2705897 (A/C) } & $\mathrm{C}$ allele & $33 / 126$ & $56 / 248$ & $1.22(0.74-2.00)$ & 0.44 & - & - & \multirow[t]{4}{*}{ Fixed } \\
\hline & $\mathrm{AC}+\mathrm{CC}$ & $25 / 63$ & $52 / 124$ & $0.91(0.49-1.69)$ & 0.77 & - & - & \\
\hline & $\mathrm{CC}$ & $8 / 63$ & $4 / 124$ & $4.36(1.26-15.11)$ & 0.02 & - & - & \\
\hline & $\mathrm{AC}$ & $17 / 63$ & $48 / 124$ & $0.59(0.30-1.14)$ & 0.11 & - & - & \\
\hline \multirow[t]{4}{*}{ rs1049216 (T/C) } & $\mathrm{C}$ allele & $360 / 1272$ & $754 / 2310$ & $0.81(0.69-0.95)$ & 0.01 & 0.54 & $0 \%$ & \multirow[t]{4}{*}{ Fixed } \\
\hline & $\mathrm{TC}+\mathrm{CC}$ & $299 / 636$ & $613 / 1155$ & $0.78(0.63-0.97)$ & 0.02 & 0.85 & $0 \%$ & \\
\hline & $\mathrm{CC}$ & $61 / 636$ & $141 / 1155$ & $0.71(0.48-1.04)$ & 0.08 & 0.13 & $52 \%$ & \\
\hline & $\mathrm{TC}$ & $238 / 636$ & $472 / 1155$ & $0.88(0.72-1.08)$ & 0.22 & 0.64 & $0 \%$ & \\
\hline \multirow[t]{4}{*}{ rs6948 (C/A) } & A allele & $519 / 1146$ & $1023 / 2086$ & $0.87(0.75-1.01)$ & 0.06 & 0.36 & $0 \%$ & \multirow[t]{4}{*}{ Fixed } \\
\hline & $\mathrm{CA}+\mathrm{AA}$ & $402 / 573$ & $777 / 1043$ & $0.80(0.63-1.02)$ & 0.07 & 0.81 & $0 \%$ & \\
\hline & AA & $117 / 573$ & $246 / 1043$ & $0.85(0.66-1.10)$ & 0.22 & 0.19 & $43 \%$ & \\
\hline & $\mathrm{CA}$ & $285 / 573$ & $531 / 1043$ & $0.94(0.76-1.16)$ & 0.55 & 0.39 & $0 \%$ & \\
\hline \multirow[t]{4}{*}{ rs12108497 (A/G) } & G allele & $281 / 878$ & $278 / 872$ & $0.90(0.34-2.36)$ & 0.83 & $<0.001$ & $95 \%$ & \multirow[t]{4}{*}{ Random } \\
\hline & $\mathrm{AG}+\mathrm{GG}$ & $240 / 439$ & $238 / 436$ & $0.85(0.25-2.85)$ & 0.79 & $<0.001$ & $95 \%$ & \\
\hline & GG & $41 / 439$ & $40 / 436$ & $0.82(0.16-4.20)$ & 0.81 & 0.001 & $90 \%$ & \\
\hline & AG & $199 / 439$ & $198 / 436$ & $0.93(0.48-1.79)$ & 0.82 & 0.02 & $82 \%$ & \\
\hline
\end{tabular}

Cases and controls are reported as number of individuals/total individuals. OR $=$ odds ratio; $95 \% \mathrm{CI}=95 \%$ confidence interval.

\section{Association between CASP-7 gene polymorphisms and cancer risk}

Associations between CASP-7 gene polymorphisms and cancer risk are shown in Table 4. The pooled analysis showed that the T allele of rs $12415607, \mathrm{G}$ allele and homozygote (GG) of rs2227310, and homozygote (CC) of rs3124740 had positive associations with cancer risk $(\mathrm{OR}=1.18,95 \% \mathrm{CI}=1.02-1.37, \mathrm{P}=0.03 ; \mathrm{OR}=1.17,95 \% \mathrm{CI}=1.01-1.34, \mathrm{P}=0.03 ; \mathrm{OR}=$ $1.34,95 \% \mathrm{CI}=1.04-1.74, \mathrm{P}=0.03$; and $\mathrm{OR}=1.30,95 \% \mathrm{CI}=1.04-1.63, \mathrm{P}=0.02$, respectively). In addition, homozygote $\mathrm{AA}$ of rs 11196418 showed a significant negative association with cancer risk $(\mathrm{OR}=0.36,95 \% \mathrm{CI}=0.14-0.93, \mathrm{P}=0.03$; Figure 3$)$. Nevertheless, no significant associations were found between rs 10787498 and rs 11593766 and cancer risk (all $\mathrm{P}>0.05$ ). Sensitivity analysis was conducted by omitting single studies, and no influence was found in the significance of the pooled OR. 
CASP-3

\begin{tabular}{|c|c|c|c|c|c|c|c|c|}
\hline \multirow{2}{*}{$\begin{array}{l}\text { rs } 2705897^{*} \mathrm{CC} \\
\text { Study or Subgroup } \\
\end{array}$} & \multicolumn{2}{|c|}{ Experimental } & \multirow{2}{*}{\multicolumn{2}{|c|}{ Control }} & & Odds Ratio & \multirow{2}{*}{\multicolumn{2}{|c|}{$\begin{array}{c}\text { Odds Ratio } \\
\text { M-H, Fixed, 95\% } \% \text { Cl }\end{array}$}} \\
\hline & Events & Total & & Total & Weight & M-H, Fixed, $95 \% \mathrm{Cl}$ & & \\
\hline & 8 & 63 & 4 & 124 & $100.0 \%$ & $4.36[1.26,15.11]$ & & \\
\hline Total $(95 \% \mathrm{Cl})$ & & 63 & & 124 & $100.0 \%$ & $4.36[1.26,15.11]$ & & \\
\hline Total events & 8 & & 4 & & & & & \\
\hline \multicolumn{3}{|c|}{$\begin{array}{l}\text { Heterogeneity: Not applicable } \\
\text { Test for overall effect: } Z=2.33(P=0.02)\end{array}$} & & & & & $\begin{array}{ll}0.01 & 0.1 \\
\text { Favor control } & 1\end{array}$ & $\begin{array}{l}10 \\
\text { Favor case }\end{array}$ \\
\hline rs $1049216^{\star} \mathrm{TC}+\mathrm{CC}$ & \multicolumn{2}{|c|}{ Experimental } & \multicolumn{2}{|c|}{ Control } & & Odds Ratio & \multirow{2}{*}{\multicolumn{2}{|c|}{$\begin{array}{c}\text { Odds Ratio } \\
\text { M-H. Fixed, } 95 \% \mathrm{Cl}\end{array}$}} \\
\hline Study or Subgroup & Events & Total & Events & Total & Weight & M-H, Fixed, $95 \% \mathrm{Cl}$ & & \\
\hline Xie et al. 2004 & 61 & 63 & 120 & 124 & $1.3 \%$ & $1.02[0.18,5.71]$ & & \\
\hline Lan et al. 2007 & 185 & 451 & 252 & 525 & $71.2 \%$ & $0.75[0.58,0.97]$ & & \\
\hline Hosgood et al. 2008 & 53 & 122 & 241 & 506 & $27.5 \%$ & $0.84[0.57,1.26]$ & & \\
\hline Total $(95 \% \mathrm{Cl})$ & & 636 & & 1155 & $100.0 \%$ & $0.78[0.63,0.97]$ & $\checkmark$ & \\
\hline Total events & 299 & & 613 & & & & & \\
\hline \multicolumn{7}{|c|}{$\begin{array}{l}\text { Heterogeneity: } \mathrm{Chi}^{2}=0.31, \text { d.f. }=2(P=0.85) ;\left.\right|^{2}=0 \% \\
\text { Test for overall effect: } Z=2.27(P=0.02)\end{array}$} & $\begin{array}{lll}0.01 & 0.1 & 1 \\
\text { Favor control } & \end{array}$ & Favor case \\
\hline rs $1049216^{*} \mathrm{C}$ allele & \multicolumn{2}{|c|}{ Experimental } & \multirow{2}{*}{\multicolumn{2}{|c|}{$\begin{array}{c}\text { Control } \\
\text { Events Total }\end{array}$}} & & Odds Ratio & \multirow{2}{*}{\multicolumn{2}{|c|}{$\begin{array}{l}\text { Odds Ratio } \\
\text { M-H. Fixed. } 95 \% \mathrm{Cl}\end{array}$}} \\
\hline Study or Subgroup & Events & Total & & & Weight & M-H, Fixed, $95 \% \mathrm{Cl}$ & & \\
\hline Xie et al. 2004 & 99 & 126 & 192 & 248 & $8.8 \%$ & $1.07[0.64,1.80]$ & & \\
\hline Lan et al. 2007 & 206 & 902 & 288 & 1050 & $65.1 \%$ & $0.78[0.64,0.96]$ & & \\
\hline Hosgood et al. 2008 & 55 & 244 & 274 & 1012 & $26.1 \%$ & $0.78[0.56,1.09]$ & - & \\
\hline Total $(95 \% \mathrm{Cl})$ & & 1272 & & 2310 & $100.0 \%$ & $0.81[0.69,0.95]$ & $\checkmark$ & \\
\hline Total events & 360 & & 754 & & & & & \\
\hline $\begin{array}{l}\text { Heterogeneity: } \text { Chi }^{2}=1.2 \\
\text { Test for overall effect: } Z\end{array}$ & $\begin{array}{l}24, \text { d.f. }=2(F \\
=2.52(P=\end{array}$ & $\begin{array}{l}P=0.54) \\
0.01)\end{array}$ & $; l^{2}=0 \%$ & & & & $\begin{array}{ll}0.01 & 0.1\end{array}$ & Favor case \\
\hline
\end{tabular}

Figure 2. Association between CASP-3 gene polymorphisms and cancer risk.

Table 4. Meta-analysis of the association between CASP-7 polymorphisms and cancer risk.

\begin{tabular}{|c|c|c|c|c|c|c|c|c|}
\hline \multirow[t]{2}{*}{ Polymorphisms } & & \multirow[t]{2}{*}{ Cancer } & \multirow[t]{2}{*}{ Control } & \multirow[t]{2}{*}{ OR $(95 \% \mathrm{CI})$} & \multirow[t]{2}{*}{$P$ value } & \multicolumn{2}{|c|}{ Heterogeneity } & \multirow[t]{2}{*}{ Effect model } \\
\hline & & & & & & $\mathrm{P}$ & $\mathrm{I}^{2}$ & \\
\hline \multirow[t]{4}{*}{ rs12415607 (G/T) } & $\mathrm{T}$ allele & $584 / 1440$ & $527 / 1440$ & $1.18(1.02-1.37)$ & 0.03 & - & - & \multirow[t]{4}{*}{ Fixed } \\
\hline & $\mathrm{GT}+\mathrm{TT}$ & $460 / 720$ & $427 / 720$ & $1.21(0.98-1.50)$ & 0.07 & - & - & \\
\hline & TT & $124 / 720$ & $100 / 720$ & $1.29(0.97-1.72)$ & 0.08 & - & - & \\
\hline & GT & $336 / 720$ & $327 / 720$ & $1.05(0.85-1.29)$ & 0.63 & - & - & \\
\hline \multirow[t]{4}{*}{ rs $10787498(\mathrm{G} / \mathrm{T})$} & $\mathrm{T}$ allele & $2804 / 3496$ & $2771 / 3444$ & $0.98(0.87-1.11)$ & 0.78 & 0.43 & $0 \%$ & \multirow[t]{4}{*}{ Fixed } \\
\hline & $\mathrm{GT}+\mathrm{TT}$ & $1662 / 1748$ & $1663 / 1722$ & $0.69(0.39-1.21)$ & 0.19 & 0.10 & $64 \%$ & \\
\hline & TT & $1142 / 1748$ & $1108 / 1722$ & $1.04(0.91-1.20)$ & 0.55 & 0.73 & $0 \%$ & \\
\hline & GT & $520 / 1748$ & $555 / 1722$ & $0.89(0.77-1.03)$ & 0.11 & 0.83 & $0 \%$ & \\
\hline \multirow{4}{*}{ rs2227310 (C/G) } & G allele & $685 / 1662$ & $624 / 1660$ & $1.17(1.01-1.34)$ & 0.03 & 0.20 & $39 \%$ & \multirow{4}{*}{ Fixed } \\
\hline & $\mathrm{CG}+\mathrm{GG}$ & $528 / 831$ & $501 / 830$ & $1.15(0.94-1.40)$ & 0.18 & 0.63 & $0 \%$ & \\
\hline & GG & $157 / 831$ & $123 / 830$ & $1.34(1.04-1.74)$ & 0.03 & 0.15 & $14 \%$ & \\
\hline & CG & $371 / 831$ & $378 / 830$ & $0.96(0.80-1.17)$ & 0.71 & 0.34 & $0 \%$ & \\
\hline \multirow[t]{4}{*}{ rs11196418 (G/A) } & A allele & $209 / 2056$ & $216 / 2002$ & $0.94(0.77-1.14)$ & 0.52 & - & - & \multirow[t]{4}{*}{ Fixed } \\
\hline & $\mathrm{GA}+\mathrm{AA}$ & $203 / 1028$ & $200 / 1001$ & $0.99(0.79-1.23)$ & 0.90 & - & - & \\
\hline & $\mathrm{AA}$ & $6 / 1028$ & $16 / 1001$ & $0.36(0.14-0.93)$ & 0.03 & - & - & \\
\hline & GA & $197 / 1028$ & $184 / 1001$ & $1.05(0.84-1.32)$ & 0.65 & - & - & \\
\hline \multirow[t]{4}{*}{ rs11593766 (T/G) } & G allele & $309 / 3490$ & $330 / 3442$ & $0.93(0.63-1.35)$ & 0.69 & 0.02 & $81 \%$ & \multirow[t]{4}{*}{ Random } \\
\hline & $\mathrm{TG}+\mathrm{GG}$ & $297 / 1745$ & $315 / 1721$ & $0.93(0.61-1.42)$ & 0.73 & 0.02 & $83 \%$ & \\
\hline & GG & $12 / 1745$ & $15 / 1721$ & $0.79(0.37-1.69)$ & 0.54 & 0.84 & $0 \%$ & \\
\hline & TG & $285 / 1745$ & $300 / 1721$ & $0.94(0.61-1.45)$ & 0.77 & 0.02 & $83 \%$ & \\
\hline \multirow[t]{4}{*}{ rs3124740 (G/C) } & $\mathrm{C}$ allele & $916 / 2054$ & $826 / 1968$ & $1.11(0.98-1.26)$ & 0.09 & - & - & \multirow[t]{4}{*}{ Fixed } \\
\hline & $\mathrm{GC}+\mathrm{CC}$ & $701 / 1027$ & $660 / 984$ & $1.06(0.88-1.27)$ & 0.57 & - & - & \\
\hline & $\mathrm{CC}$ & $215 / 1027$ & $166 / 984$ & $1.30(1.04-1.63)$ & 0.02 & - & - & \\
\hline & $\mathrm{GC}$ & $486 / 1027$ & $494 / 984$ & $0.89(0.75-1.06)$ & 0.20 & - & - & \\
\hline
\end{tabular}

Cases and controls are reported as number of individuals/total individuals. OR = odds ratio; $95 \% \mathrm{CI}=95 \%$ confidence interval. 


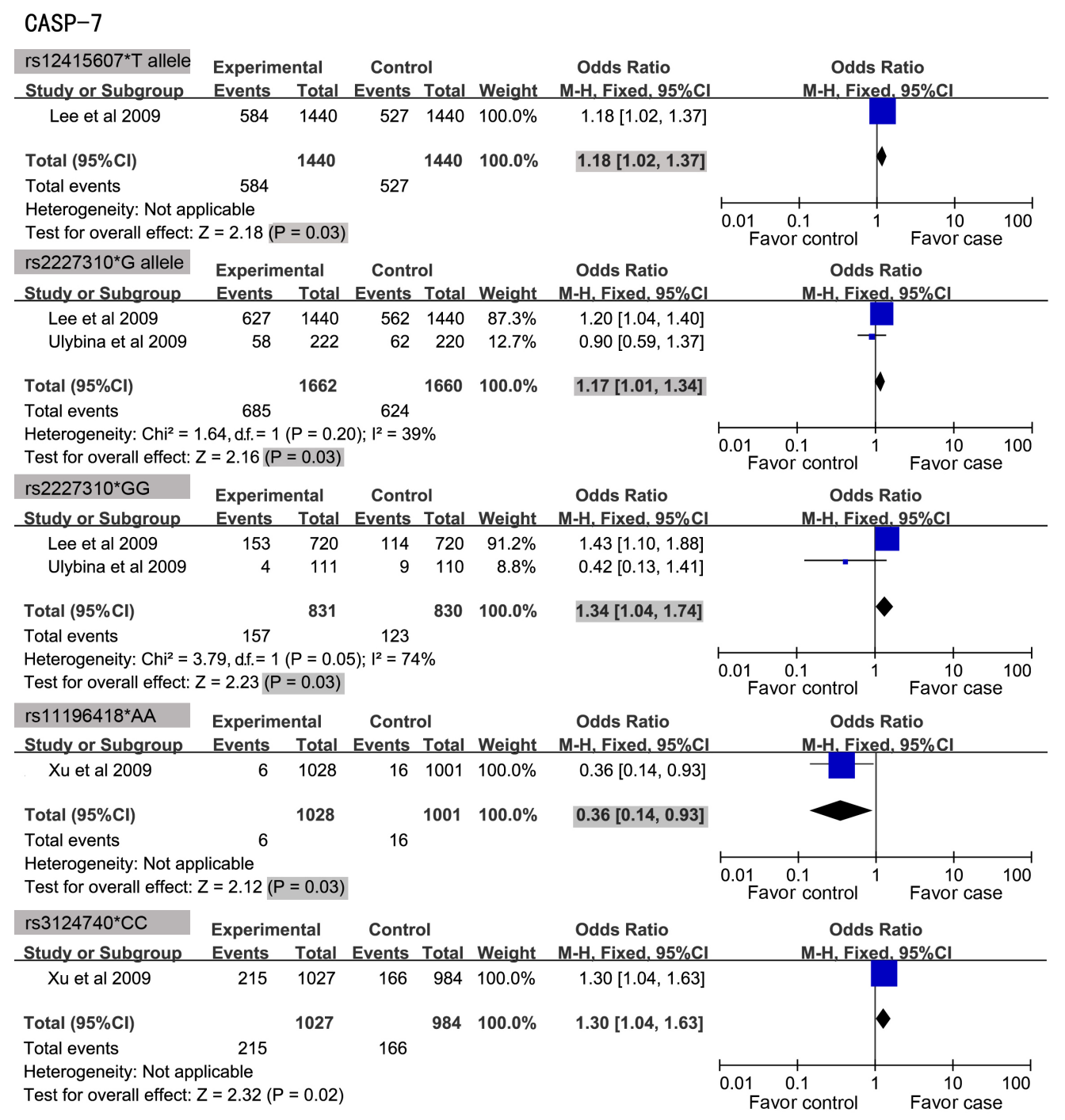

Figure 3. Association between CASP-7 gene polymorphisms and cancer risk.

\section{Publication bias}

Publication bias was assessed based on rs 1049216 in CASP-3 using the Begger funnel plot and the Egger linear regression test, which was used to measure the asymmetry of the funnel plot. All graphical funnel plots of the studies included appeared to be symmetrical (Figure 4). The Egger test also revealed no statistical significance for all evaluations of publication bias (all $\mathrm{P}>0.05$ ). The findings of the Egger publication bias test are shown in Table 5 . 

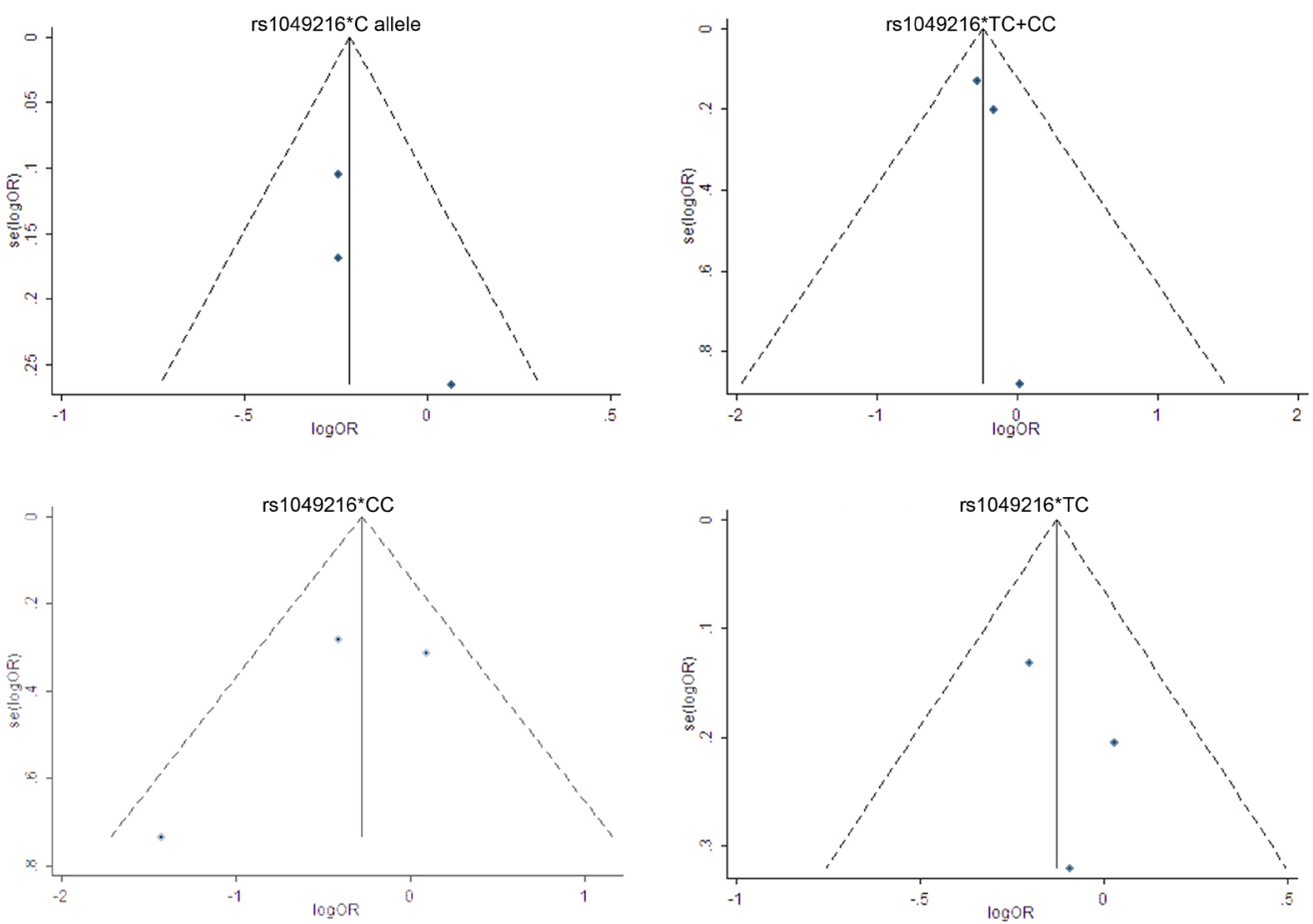

Figure 4. Begger funnel plot of publication bias based on rs 1049216 in the CASP-3 gene.

Table 5. Evaluation of publication bias based on rs 1049216 by the Egger linear regression test.

\begin{tabular}{lccccc}
\hline Comparison & Coefficient & SE & $t$ & $\mathrm{P}$ & \multicolumn{1}{c}{$95 \%$ CI } \\
\hline T allele & 1.576 & 0.982 & 1.600 & 0.355 & $(-10.908,14.059)$ \\
TC + CC & 0.509 & 0.387 & 1.320 & 0.414 & $(-4.411,5.430)$ \\
CC & -2.514 & 2.418 & -1.040 & 0.488 & $(-33.231,28.203)$ \\
TC & 1.027 & 1.301 & 0.790 & 0.575 & $(-15.499,17.552)$ \\
\hline
\end{tabular}

$\mathrm{SE}=$ standard error; $95 \% \mathrm{CI}=95 \%$ confidence interval.

\section{DISCUSSION}

Apoptosis plays an important role in protecting hosts from cancer development by eliminating DNA-damaged cells (Mittal et al., 2012). An imbalance between cell death and proliferation may lead to cancer. Two main apoptotic pathways occur in humans: extrinsic and intrinsic (Theodoropoulos et al., 2011). During the apoptotic process, both of these pathways use the caspase enzyme cascade: the extrinsic pathway includes caspase- 8 and -10 , whereas the intrinsic pathway includes caspase- 9 , and they converge to use caspase- $3,-6$, and -7 as effector caspases (Nicholson and Thornberry, 1997; Hajra and Liu, 2004; Kesarwani et al., 2011).

Caspase-3 is one of the key actors in apoptosis, being responsible either partially or totally for the proteolytic cleavage of many key proteins. CASP-3 mutation has been reported in 
the MCF-7 breast cancer cell line (Kurokawa et al., 1999), suggesting the presence of CASP-3 mutation in human cancer tissues. Soung et al. (2004) detected CASP-3 mutations in several types of tumors, including 4 of 98 colon carcinomas (4.1\%), 4 of 181 non-small cell lung cancers (2.2\%), 2 of 129 non-Hodgkin lymphomas (1.6\%), 2 of 165 stomach carcinomas (1.2\%), 1 of 80 hepatocellular carcinomas (1.3\%), and 1 of 28 multiple myelomas (3.6\%). This presence indicates that the CASP-3 gene occasionally mutates in human tumors. Caspase- 7 is another effector caspase that is comparatively important to caspase- 3 in apoptosis execution, especially in cells with deficient or underexpressed caspase-3. Caspase-7, which is an important intracellular effector of granzyme B-mediated apoptosis and cytotoxic T-lymphocyte-induced cell killing, might act as a negative regulator of apoptosis.

An immunohistochemical study has revealed a downregulation of caspase-7 in colon cancer samples compared with that in normal colon mucosa (Palmerini et al., 2001). Soung et al. (2003) also observed CASP-7 gene mutations in several types of human solid cancers, including 2 of 98 colon carcinomas (2.0\%), 1 of 50 esophageal carcinomas (2.0\%), and 1 of 33 head and neck carcinomas (3.0\%). To assess the role of CASP-3 and CASP-7 genetic polymorphisms in cancer susceptibility, we conducted a HuGE review and meta-analysis to clarify these associations.

Overall, our fixed-effect model analysis showed that the homozygote of rs 2705897 in the CASP-3 gene might increase the risk of cancer. Similarly, the T allele of rs $12415607, \mathrm{G}$ allele and homozygote of rs2227310, and homozygote (CC) of rs3124740 in the CASP-7 gene were also risk factors for susceptibility to cancer. Interestingly, we identified protective roles for the $\mathrm{C}$ allele and C carrier (TC + CC) of rs 1049216 in the development of carcinogenesis, which is consistent with the results of previous studies (Lan et al., 2007; Hosgood et al., 2008). In addition, the homozygote of rs11196418 in the CASP-7 gene is also a protective factor for cancer risk.

Given that the eligible number of studies in this meta-analysis was small, these results require further investigation. Furthermore, some limitations in this meta-analysis should be addressed: 1) the analysis was based on unadjusted OR estimates because not all published studies presented adjusted ORs or presented ORs that were not adjusted by the same potential confounders, such as age, gender, ethnicity, and exposure; 2) significant between-study heterogeneity was present in studies of the caspase-3 polymorphism, and the genotype distribution also showed deviation from HWE in one study; 3 ) the number of studies and number of subjects in the studies included in the meta-analysis were small, and some relevant studies were excluded from our analysis owing to incomplete raw data; 4) although the cases and controls of each study were well defined with similar inclusion criteria, factors that were not taken into account may have influenced our results; and 5) meta-analysis is a retrospective research that is subject to methodological limitations.

In conclusion, this meta-analysis of 9 case-control studies demonstrated that CASP-3 and CASP-7 genetic polymorphisms are involved in the pathogenesis of variant cancer. Because few studies are available in this field, current evidence remains limited. Therefore, we emphasize the necessity of conducting large studies with adequate methodological quality and proper control of confounds to obtain valid results.

\section{ACKNOWLEDGMENTS}

We thank J.L. Liu (MedChina Medical Information Service Co., Ltd.) for valuable contributions and revision of the manuscript. 


\section{REFERENCES}

Budihardjo I, Oliver H, Lutter M, Luo X, et al. (1999). Biochemical pathways of caspase activation during apoptosis. Annu. Rev. Cell Dev. Biol. 15: 269-290.

Cohen GM (1997). Caspases: the executioners of apoptosis. Biochem. J. 326: 1-16.

Devarajan E, Sahin AA, Chen JS, Krishnamurthy RR, et al. (2002). Down-regulation of caspase 3 in breast cancer: a possible mechanism for chemoresistance. Oncogene 21: 8843-8851.

Evan GI and Vousden KH (2001). Proliferation, cell cycle and apoptosis in cancer. Nature 411: 342-348.

Hajra KM and Liu JR (2004). Apoptosome dysfunction in human cancer. Apoptosis 9: 691-704.

He X, Chang S, Zhang J, Zhao Q, et al. (2008). MethyCancer: the database of human DNA methylation and cancer. Nucleic Acids Res. 36: D836-D841.

Higgins JP and Thompson SG (2002). Quantifying heterogeneity in a meta-analysis. Stat. Med. 21: 1539-1558.

Hosgood HD III, Baris D, Zhang Y, Zhu Y, et al. (2008). Caspase polymorphisms and genetic susceptibility to multiple myeloma. Hematol. Oncol. 26: 148-151.

Isobe N, Onodera H, Mori A, Shimada Y, et al. (2004). Caspase-3 expression in human gastric carcinoma and its clinical significance. Oncology 66: 201-209.

Kesarwani P, Mandal RK, Maheshwari R and Mittal RD (2011). Influence of caspases 8 and 9 gene promoter polymorphism on prostate cancer susceptibility and early development of hormone refractory prostate cancer. BJU Int. 107: 471-476.

Kurokawa H, Nishio K, Fukumoto H, Tomonari A, et al. (1999). Alteration of caspase-3 (CPP32/Yama/apopain) in wildtype MCF-7, breast cancer cells. Oncol. Rep. 6: 33-37.

Lakhani SA, Masud A, Kuida K, Porter GA Jr, et al. (2006). Caspases 3 and 7: key mediators of mitochondrial events of apoptosis. Science 311: 847-851.

Lan Q, Zheng T, Chanock S, Zhang Y, et al. (2007). Genetic variants in caspase genes and susceptibility to non-Hodgkin lymphoma. Carcinogenesis 28: 823-827.

Lee WK, Kim JS, Kang HG, Cha SI, et al. (2009). Polymorphisms in the Caspase7 gene and the risk of lung cancer. Lung Cancer 65: 19-24.

Lei YR (2010). Polymorphism of Caspase-3-928A/G Associated with the Risk and Aggressiveness of Colorectal Cancer in Chinese Population. Master's thesis, Huazhong University of Science and Technology, Tongji Medical College, Wuhan.

Mittal RD, Mittal T, Singh AK and Mandal RK (2012). Association of caspases with an increased prostate cancer risk in north Indian population. DNA Cell Biol. 31: 67-73.

Ni Q, Jiang X, Jin MJ, Liu B, et al. (2011). Association of CASP3 and CASP9 polymorphisms with genetic susceptibility to stomach cancer. Zhonghua Yi Xue Yi Chuan Xue Za Zhi 28: 318-322.

Nicholson DW and Thornberry NA (1997). Caspases: killer proteases. Trends Biochem. Sci. 22: 299-306.

Palmerini F, Devilard E, Jarry A, Birg F, et al. (2001). Caspase 7 downregulation as an immunohistochemical marker of colonic carcinoma. Hum. Pathol. 32: 461-467.

Peters JL, Sutton AJ, Jones DR, Abrams KR, et al. (2006). Comparison of two methods to detect publication bias in metaanalysis. JAMA 295: 676-680.

Son JW, Kang HK, Chae MH, Choi JE, et al. (2006). Polymorphisms in the caspase-8 gene and the risk of lung cancer. Cancer Genet. Cytogenet. 169: 121-127.

Soung YH, Lee JW, Kim HS, Park WS, et al. (2003). Inactivating mutations of CASPASE-7 gene in human cancers. Oncogene 22: 8048-8052.

Soung YH, Lee JW, Kim SY, Park WS, et al. (2004). Somatic mutations of CASP3 gene in human cancers. Hum. Genet. 115: 112-115.

Teixeira VH, Jacq L, Lasbleiz S, Hilliquin P, et al. (2008). Genetic and expression analysis of CASP7 gene in a European Caucasian population with rheumatoid arthritis. J. Rheumatol. 35: 1912-1918.

Theodoropoulos GE, Gazouli M, Vaiopoulou A, Leandrou M, et al. (2011). Polymorphisms of caspase 8 and caspase 9 gene and colorectal cancer susceptibility and prognosis. Int. J. Colorectal Dis. 26: 1113-1118.

Thompson CB (1995). Apoptosis in the pathogenesis and treatment of disease. Science 267: 1456-1462.

Ulybina YM, Kuligina ESh, Mitiushkina NV, Rozanov ME, et al. (2009). Coding polymorphisms in Casp5, Casp8 and DR4 genes may play a role in predisposition to lung cancer. Cancer Lett. 278: 183-191.

von Elm E, Altman DG, Egger M, Pocock SJ, et al. (2007). The strengthening the reporting of observational studies in epidemiology (STROBE) statement: guidelines for reporting observational studies. Epidemiology 18: 800-804.

Wang JX and Zheng S (2004). Caspase-3 and survivin expression in pediatric neuroblastoma and their roles in apoptosis. Chin. Med. J. 117: 1821-1824. 
Xie Y (2004). The Polymorphisms and Mutation in Caspase 3 and Fas Gene on Healthy People and B-NHL Patients of Han Nationality in China, and Discuss Their Relationships with the Pathogenesis of B-NHL. Master's thesis, Zhejiang University, School of Medicine, Hangzhou.

Xu HL, Xu WH, Cai Q, Feng M, et al. (2009). Polymorphisms and haplotypes in the caspase-3, caspase-7, and caspase-8 genes and risk for endometrial cancer: a population-based, case-control study in a Chinese population. Cancer Epidemiol. Biomarkers Prev. 18: 2114-2122.

$\mathrm{Yu}$ CH, Kan SF, Shu CH, Lu TJ, et al. (2009). Inhibitory mechanisms of Agaricus blazei Murill on the growth of prostate cancer in vitro and in vivo. J. Nutr. Biochem. 20: 753-764.

Zhang L, Liu JL, Zhang YJ and Wang H (2011). Association between HLA-B*27 polymorphisms and ankylosing spondylitis in Han populations: a meta-analysis. Clin. Exp. Rheumatol. 29: 285-292.

Zintzaras E and Ioannidis JP (2005). Heterogeneity testing in meta-analysis of genome searches. Genet. Epidemiol. 28: 123-137. 